\title{
LA MEDIACIÓN EN CHINA CONTINENTAL: ORÍGENES Y REGULACIÓN ACTUAL
}

\section{Mediation in mainland China: origins and current regulation}

Mauricio Eduardo Ríos Lagos* PONTIFICIA UNIVERSIDAD CATÓLICA DE VALPARAÍSO VALPARAÍSO, CHILE

* Licenciado en Ciencias Jurídicas por la Pontificia Universidad Católica de Valparaíso. Máster universitario en Derecho Empresa y justicia por la Universidad de Valencia (España). Master of LAWS (LL.M.) Cornell University (EEUU). Correo electrónico: mauricioriosl@gmail.com

Artículo recibido el 23 de febrero de 2018 y aceptado para publicación el 22 de mayo de 2018 
RESUMEN: El presente trabajo presenta un estudio sobre los orígenes de la mediación en China Continental y la regulación actualmente aplicable a a ella. El autor discute la influencia que ha tenido el colectivismo y el confucionismo sobre la institución y la sociedad china lo que ha llevado a su utilización por sobre el proceso judicial. Asimismo, se presentan dos tipos de mediación: La mediación popular y la mediación judicial. Finalmente, se identifican los problemas que se han observado en la práctica con cada una de ellas.

PALABRAS CLAVE: mediación, confucionismo, colectivismo, mediación popular, mediación judicial

ABSTRACT: This paper presents a study on the origins of mediation in Mainland China and the regulations currently applicable to it. The author discusses the influence that collectivism and Confucianism have had on the institution and in Chinese society, which has led to its use over the judicial process. There are also two types of mediation: People's mediation and judicial mediation. Finally, identified are the problems that have been observed in legal practice with each of them.

KEYWORDS: Mediation, confucianism, collectivism, people's mediation, judicial mediation 


\section{INTRODUCCIÓN}

La resolución alternativa de conflictos es un tema que en las últimas décadas ha logrado una gran prominencia en la doctrina y práctica legal. Tradicionalmente, la litigación y el arbitraje han sido las formas más utilizadas de resolución de disputas en la cultura occidental y por ello gran parte de los estudios científicos se ha centrado en estos dos métodos de resolución de controversias.

No es una novedad que en la actualidad la litigación presenta problemas. Los tribunales estatales poseen una gran cantidad de casos no resueltos y los gobiernos de turno han tratado de implementar herramientas para descongestionar el sistema judicial con el objetivo de lograr disminuir los tiempos de respuesta y, en última instancia, evitar la injusticia por falta o demora en el acceso a los órganos jurisdiccionales. En este escenario, el arbitraje y la mediación han sido las herramientas elegidas por los Estados para ofrecer una nueva vía o camino para la resolución de conflictos.

Abordaré la mediación, cuyas raíces son antiguas en las culturas occidentales y orientales. Sin embargo, la mediación en las culturas orientales se ha desarrollado de forma diversa a la occidental, ello fuertemente vinculado con el modo de afrontar los conflictos en sus sociedades.

Se analiza específicamente a la mediación en la China continental y la pregunta que voy a tratar de responder en estas líneas es: ¿ Por qué China ha utilizado con éxito la mediación como un método de resolución de disputas?

El estudio de la mediación en China continental puede ser útil no sólo para comprender acabadamente la institución de la mediación en un contexto global, sino también para obtener una comprensión más acabada del sistema legal chino, que actualmente está siendo objeto de diversos estudios debido a la importancia del país como potencia económica en el escenario mundial.

Este trabajo se divide en cinco partes: La primera de ellas aborda el concepto de mediación en China continental y en el mundo occidental; la segunda trata sobre los orígenes de la mediación en China; la tercera versa sobre la media- 
ción en la China tradicional; la cuarta parte recoge dos tipos de mediación en la República Popular China: la Mediación Popular y la Mediación Judicial; y finalmente, la quinta es la conclusión sobre lo investigado.?

\section{EL CONCEPTO DE MEDIACIÓN EN CHINA}

La primera idea que debemos precisar es qué estamos hablando cuando nos referimos a la mediación. En término generales, la resolución de conflictos en una sociedad puede llevarse a cabo a través de métodos autocompositivos y heterecompositivos. ${ }^{2}$ Dentro de los primeros encontramos a la mediación y a la conciliación, mientras que dentro de los últimos nos encontramos al arbitraje y la litigación ante tribunales de justicia. ${ }^{3}$

Como un elemento de los métodos autocompositivos podemos destacar que las partes son las que llegan a un acuerdo y el rol del tercero es acercarlas, proponer soluciones, siendo que éstas no son vinculantes para ellas. La diferencia entre la mediación y la conciliación radica en el hecho que el mediador utiliza técnicas de aproximación y hace partícipes a las partes en la solución del conflicto, mientras que el conciliador carece de ellas y puede trabajar en forma conjunta o separada con las partes con el fin de que lleguen a un acuerdo. ${ }^{4}$ En cambio, en el arbitraje y en la litigación hay un tercero imparcial que tiene el poder de resolver la disputa y que su resolución sea vinculante para las partes. ${ }^{5}$

Es así como la mediación, considerada método autocompositivo, se ha definido como "un proceso por el cual los participantes, junto con la ayuda de una persona o personas imparciales, tratan sistemáticamente los temas en disputa con el fin de desarrollar opciones, considerar alternativas y alcanzar un acuerdo consensual que satisfaga sus necesidades ${ }^{\prime \prime}{ }^{6}$ Como

1 El presente trabajo solo tiene por objeto el estudio de la mediación en la China continental, dejando de lado a Hong Kong por las influencias ejercidas por el Imperio Británico.

2 Dejamos de lado como método de resolución la autodefensa o autotutela por su carácter excepcional en los ordenamientos jurídicos.

3 Barona (2011) pp. 187 y 188.

4 Barona (2014) pp. 187-188.

5 Barona (2011) p.188.

6 FOLBERG Y TAYLOR (1984) p. 7. 
señalé con anterioridad, uno de los elementos claves de la mediación, es el hecho de que el/los tercero/s neutral/es no tienen autoridad para tomar decisiones vinculantes para las partes.

En China continental, el término utilizado para lo que nosotros llamamos mediación es tiaojie (解), pero algunos estudios han coincidido en que este término no es comparable con el término occidental de mediación o conciliación. ${ }^{7}$ Por otro lado, algunos autores han señalado que no existiría diferencia alguna entre los términos de mediación y de conciliación. ${ }^{8}$

El primer rasgo diferenciador entre la mediación de Occidente y la que se desarrolla en China continental proviene del papel o función que desempeña el mediador. En dicho país, el mediador tiene un rol claramente prominente, distinto a la cultura occidental. De acuerdo a este rol, un mediador "puede ser intervencionista, proactivo e incluso dictatorial, y ciertamente se puede esperar que sea autoritario". ${ }^{9}$ Así, por ejemplo, una de las principales críticas que se realiza a la mediación judicial es que el juez/mediador abusa de su autoridad ya que de forma indirecta fuerza a las partes a solucionar las disputas a través de la mediación y no del proceso judicial. ${ }^{10}$

Como veremos más adelante, la razón de ser de este modo de actuar de parte del mediador o del juez, se basaría en la idea del colectivismo, presente en las raíces de la cultura china ${ }^{11}$ que busca evitar el conflicto individual en busca del bienestar social.

\section{LAS RAÍCES DE LA MEDIACIÓN EN CHINA CONTINENTAL}

En China continental, la mediación ha sido utilizada durante mucho tiempo como un eficaz método de resolución de controversias y sus primeras manifestaciones se pueden encontrar durante la época de los Cinco

\footnotetext{
7 Hilmer (2009) p. 11.

8 YUANSHIY XUYANG (2015) p. 192.

9 GOH (2002) p. 15.

10 LeE (2014) p. 109.

11 GoH (2OO2) p. 15.
} 
Emperadores (3076 a.C.-2029 a.C.). 12 Sin embargo, la mediación como un sistema organizado y reconocido formalmente tiene sus antecedentes durante las dinastías Ming (1368-1644) y Qing (1644-1911). ${ }^{13}$

Algunos autores han señalado que el desarrollo de la mediación pudo atribuirse a las propias características de la cultura china las cuales permitieron que la institución evolucionara de forma natural e imperceptible y de una manera profundamente significativa. ${ }^{14}$ La cultura como influencia es una importante idea para entender la filosofía y los principios detrás de la sociedad china con el objetivo de establecer alguna diferencia con el enfoque occidental de la mediación.

Asimismo dos aspectos esenciales se han identificado como propulsores del desarrollo de la mediación en China continental: el colectivismo y el confucionismo, los cuales se encuentran aún presentes en la China contemporánea.

\section{El colectivismo en China}

El colectivismo es la primera diferencia cultural entre China y el mundo occidental. Aquí no hay prominencia del individuo por encima del grupo o de la sociedad, lo que se conoce como individualismo. En cambio, el colectivismo se enfoca en los objetivos sociales y el bienestar común.

El individuo necesita adaptarse a este entorno y "el individuo se somete a los objetivos del grupo como medio de preservar o promover su propio interés".$^{15}$ Este enfoque cultural difiere de la cultura occidental, que centra su foco en el individuo y no en el bienestar colectivo.

El colectivismo chino tiene consecuencias en la forma en que las personas valoran o analizan el conflicto y cuando un individuo enfrenta una disputa existe una fuerte preferencia para evitarlo, retirarse, comprometerse o tratar de resolver el problema. ${ }^{16}$ Esa manera de afrontar los conflictos

12 ZENG (2009) p. 3.

13 ZENG (2OO9) p. 7.

$14 \mathrm{GOH},(2 \mathrm{OO} 2)$ p. 2.

$15 \mathrm{GOH}(2 \mathrm{OO} 2)$ p. 7.

16 ZHANG (2015) p. 49. 
difiere de la forma de pensar que existe en Occidente, caracterizada como individualista y con el bien común subordinado al beneficio individual.

\section{Confucionismo en China}

Es difícil imaginar la influencia que Confucio ha tenido en China. Su nombre era Kung Qiu o Kung Chung-ni ${ }^{17}$, vivió entre 551-479 a.C ${ }^{18}$ y es reconocido como el fundador de la filosofía conocida como Confucionismo. Esta filosofía continúa presente en China contemporánea y su influencia cultural y social puede ayudarnos a explicar cómo las personas manejaban las disputas y los conflictos en la sociedad debido a que éstos eran vistos "como irrupciones de la armonía natural que unía al individuo, al grupo, a la sociedad y al universo entero". ${ }^{19}$

Para el Confucionismo el término clave era li (ritos o ceremonias) lo que constituía "tanto las instituciones concretas como los modos aceptados de comportamiento en un estado civilizado". ${ }^{20}$ Para esta filosofía, el hombre era considerado bueno por naturaleza ${ }^{21}$, en el cual solo un gobierno basado en la virtud podía obtener la aprobación del pueblo. ${ }^{22}$ Asimismo, la educación era un elemento importante y la estratificación social era reconocida. ${ }^{23}$ Así, la función de li era lograr la armonía en la sociedad. ${ }^{24}$

En cuanto a la educación, ella estaba abierta a todo el mundo y su propósito era de carácter moral, con la creencia que las conductas errantes provenían de una falta de conocimiento, de una comprensión errónea. ${ }^{25}$ Por esta razón, para prevenir la comisión de delitos y otros ilícitos, las personas necesitaban ser educadas.

En lo que se refiere a la estratificación social, existían cinco relaciones: las

\footnotetext{
17 Head y Wang (2005) p. 32.

$18 \mathrm{GOH}(2 \mathrm{OO} 2)$ p. 30.

19 Stanley (1967) p. 1291.

20 BOdde Y MORRIS (1967) p.19.

21 WANG Y MADSON (2013) p.31.

22 WANG y MADSON (2013) p. 29.

23 CLARK (2001) p. 128.

24 ZHANG (2015) p. 429.

25 HeAd Y WANG (2005) p. 40.
} 
de padre e hijo; gobernante y sujeto; marido y mujer; hermano mayor y más joven; y entre amigos. ${ }^{26}$ En esta estructura social, el confucionismo prescribía conductas o modos de comportamiento que diferían según el estatus. ${ }^{27}$

En relación con el derecho, $f a$ (ley) y el proceso judicial, Confucio pensaba que "la cohesión y el bienestar de la sociedad debe asegurarse no a través de preceptos legales sino mediante la observancia de rituales propios de $l i{ }^{\prime \prime} .^{28}$ Junto con ello, los seguidores de la filosofía estimaban que el proceso judicial no era uno de los logros más altos que había logrado la civilización China, sino que era una necesidad ${ }^{29}$ y que la intervención en los procesos judiciales gozaba de mala reputación. ${ }^{30}$

Finalmente, esta filosofía puede explicarse con más detalle a través las siguientes citas que han sido atribuidas a Confucio:"; En conocer de casos judiciales soy tan bueno como cualquier otra persona, pero lo que realmente se necesita es lograr que no haya casos!". 31 "Guía al pueblo por medio de la reglamentación, mantenlos en orden por medio de castigos, y ellos huirán de ti y perderán todo respeto propio. Pero guíalos por la virtud y mantenlos en orden por la moral establecida ( $l i)$, y ellos mantendrán su respeto y vendrán a ti". ${ }^{32}$

La idea del colectivismo y la filosofía del confucionismo están en las raíces de la cultura china. Sus aproximaciones acerca de la vida y en general de las diferentes relaciones dentro de una sociedad están entrelazadas. Una sociedad que evita el conflicto tiene las condiciones para desarrollar un enfoque diferente acerca de la resolución de disputas. Además, si su propósito había sido no tener casos, solo cabría esperar que el litigio, como forma de resolución de disputas, fuera una herramienta de último recurso en la sociedad.

\footnotetext{
26 HEAD Y WANG (2005) p.40

27 BODdE (1982) p. 132.

28 HEAD Y WANG (2005) p.39.

29 COHEN (1966) p.1206.

30 COHEN (1966) p. 1207.

31 Confucio (2014) p. 118.

32 Confucio (2014) p. 14.
} 
Con estas condiciones, la mediación en la China tradicional tuvo un escenario natural y acogedor para su desarrollo. Así, ante la existencia de un conflicto, éste era abordado por las familias o los clanes, los cuales intentaban reconciliar a las partes por medio de presión de los pares y reafirmando los valores del confucionismo. ${ }^{33}$

\section{MEDIACIÓN EN LA CHINA TRADICIONAL}

Hasta 1911 China fue gobernada por dinastías imperiales y a esta época usualmente se le denomina como China tradicional. ${ }^{34}$ En este extenso período, la mediación tuvo un importante papel como método eficaz de resolución de disputas. Durante este tiempo, diferentes tipos de mediación salieron a la luz, las que podemos clasificar en términos generales como mediación extrajudicial y mediación judicial. Dentro de la mediación extrajudicial, podemos encontrar a su vez a la mediación privada y la mediación administrativa. ${ }^{35}$

\section{Mediación privada}

En esta época la familia, el clan, la villa o los gremios tenían una labor importante al momento de resolver disputas al interior de las mismas ${ }^{36}$, a tal nivel que fueron preferidas en lugar de recurrir al sistema judicial. ${ }^{37}$ La pregunta que de inmediato surge es por qué las personas o grupos de personas prefirieron recurrir a la mediación en lugar del proceso judicial. Lubman resume las razones indicando que la misma administración de justicia desalentaba recurrir a ella, debido a que los funcionarios o yamen se encontraban generalmente lejos de las villas o gremios. Además, los funcionarios encargados no eran expertos en derecho, inclusive algunos sin formación jurídica alguna, a lo que se añadía que estaban ocupados realizando otras funciones del gobierno, por lo cual dependían en gran

33 CLARK (2001) p. 131.

34 Puede consultarse una descripción histórica de China en la obra de HeADz y WANG (2005).

35 Existen otras clasificaciones dependiendo el rol del mediador o si la mediación se conecta o no con el tribunal. Véase, por ejemplo, Lı (2017) p. 22.

$36 \mathrm{GOH}(2 \mathrm{OO} 2)$ p.70.

37 Ibid. 
medida de sus empleados y otros subalternos para asistirlos ${ }^{38}$, lo que conllevaba ineficiencia e ineficacia en la administración de la misma.

Frente a un complejo e ineficiente sistema de administración de justicia, la población (el ciudadano) recurría a la mediación ante un clan, una aldea o unidades sociales. Por ejemplo, en caso de disputas en una familia, los ancianos las resolvían. El papel de los ancianos no era sólo mediar; en algunos casos tenían la posibilidad de decidir casos. ${ }^{39}$ Si surgía un conflicto en una aldea, el jefe de ella tenía la responsabilidad de resolver la disputa; si el problema surgía en un gremio, los funcionarios de ese gremio particular tenían autoridad para resolver la disputa. Estos ejemplos pueden mostrarnos cómo la sociedad en China tradicional tenía un sistema único de respuesta en caso de disputas entre sus miembros.

Lo más interesante de este sistema informal de resolución de disputas fue, en palabras de Lubman que, "recurrir al magistrado sin intentos previos de resolver disputas dentro de los grupos fue activamente desalentado y a veces, como en el caso de clanes y gremios, prohibido por reglamentos internos de cada grupo". ${ }^{40}$

Finalmente, se puede concluir que en la China tradicional existía un método de disputa eficiente e informal y su éxito se debió en parte a las deficiencias de la justicia formal y a la importancia de las instituciones sociales como la familia, el clan, etc., que ayudaron a resolver y aislar la disputa dentro de estas instituciones.

\section{Mediación administrativa}

Este tipo de mediación, conocida también como mediación oficial ${ }^{41}$, tiene sus orígenes en la dinastía Qin (221 a.C.-207 a.C.). ${ }^{42}$ En la China antigua existieron divisiones administrativas Ilamadas Xiang (municipios), las que fueron divididas en Ting (o 10 $L i$ ) y $L i$ (consiste en un cierto número de

\footnotetext{
38 LUBMAN (1967) pp.1295-1296.

39 HiLMER (2009) p. 9.

40 LUBMAN (1967) p. 1297.

$41 \quad$ LI (2017) p.23.

42 Hilmer (2009) p.8.
} 
casas) ${ }^{43}$ y los funcionarios de alto rango dentro de este tipo de organizaciones administrativas tenían la autoridad de mediar disputas entre la población. ${ }^{44}$ Asimismo, en algunas ocasiones los funcionarios de justicia podían ejercer la labor de mediador cuando desempeñaban labores

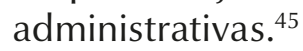

Las diferencias entre la mediación administrativa y la mediación privada radican en el hecho que la primera es llevada a cabo por oficiales de la administración, mientras que la segunda por miembros del núcleo familiar, del clan de la villa o del gremio respectivo, además la mediación administrativa se rige por normas de naturaleza civil y administrativa, mientras que la mediación privada es posible que se base tanto en normas civiles, morales e incluso en la costumbre.

\section{Mediación Judicial}

Hasta este momento, no existía ley que se refiriera a la mediación judicial en China ${ }^{46}$ Los Códigos de la ley imperial guardaban silencio sobre la misma. Sin embargo, en la práctica, las autoridades promovían la mediación como método de resolución de conflictos y, con frecuencia, los funcionarios que realizaban la labor de mediadores durante los procedimientos judiciales intentaban tecnificar a las partes acerca del Confusionismo. ${ }^{47}$

De acuerdo a Xiaobing Xu, "cuando los conflictos eran llevados a los funcionarios, éstos criticaban el hecho de no poder cumplir con sus propias obligaciones. La idea es que, si ellos hubieran hecho un mejor trabajo para educar a la población, estas disputas no habrían surgido". ${ }^{48}$ Así durante el desarrollo del procedimiento judicial, los funcionarios trataban de mediar, tratando de enviar la disputa a una mediación privada o administrativa, con el objetivo de reducir los litigios en la sociedad. ${ }^{49}$

\footnotetext{
43 HiLMER (2OOg) p.8.

44 Ibid.

45 LI (2O17) p. 22.

46 HiLMER (2OO9) p. 9.

47 Ibid.

$48 \mathrm{Xu}(2005)$ p.531.

49 Ibid.
} 
Este ejemplo muestra claramente la forma en que la sociedad china manejaba los conflictos, incluso cuando ya existía un procedimiento judicial en curso. De hecho, podemos decir que éstos eran el último recurso para resolver una disputa entre las partes, e incluso dentro del mismo, podía tener lugar el procedimiento de mediación a efectos de eliminar el conflicto y restaurar la armonía en la sociedad.

\section{MEDIACIÓN EN LA REPÚBLICA POPULAR CHINA}

\section{Introducción}

La mediación no se vio afectada durante el período de la República de China (1911-1949). ${ }^{50}$ Sin embargo, durante este período el gobierno intentó establecer un procedimiento judicial de mediación basado en el argumento que la mediación podría disminuir la congestión en los tribunales. ${ }^{51}$ Posteriormente, con el establecimiento de la República Popular en 1949 la mediación siguió evolucionando con la dictación de diversas leyes y el reconocimiento constitucional de la mediación popular en el año 1982.

\section{Consagración normativa de la mediación}

Dentro del sistema de fuentes del derecho chino, la Constitución de la República Popular China de 1982 reconoce a la mediación popular en el artículo 111, el cual establece que "los comités de residentes y aldeanos establecerán comités de mediación popular, seguridad pública, salud pública y otras materias para gestionar los asuntos públicos y servicios sociales en sus áreas, mediar en las disputas civiles, ayudar a mantener el orden público, transmitir opiniones y demandas de los residentes y hacer sugerencias al gobierno popular." ${ }^{\prime 2}$ Por su parte, el artículo 22 de la Ley Orgánica de Tribunales Populares de la República Popular de China ${ }^{53}$

50 TAO (2005) p.1013.

51 HiLmer (2009) p. 70.

52 Aprobada en la Quinta Sesión del Quinto Congreso Nacional del Pueblo y promulgada para su implementación por el Anuncio de Congreso Popular el 4 de diciembre de 1982.

53 Adoptada en la Segunda Sesión del Quinto Congreso Nacional del Pueblo el 1 de julio de 1979. 
señala que una tarea de los tribunales populares es dirigir el trabajo de los comités de mediación popular.

La Ley de Procedimiento Civil de la República Popular de China de 1982 reconocía en el Capítulo I relativo a su objetivo y principios, específicamente el artículo 6, que al llevarse a cabo un proceso civil los tribunales debían hacer énfasis en la conciliación y si ella si no lograba, los mismos debían fallar sin demora. Además, dicha ley establecía normas relativas a la conciliación en la Sección IV del Capítulo IX referido al procedimiento ordinario de primera instancia. Posteriormente, dicha la Ley del año 1982 fue reemplazada por la Ley de Procedimiento Civil de $1991^{54}$, la que a su vez en su artículo 9 estableció una norma que puso en relieve a la base voluntaria de la mediación y además incorporó un Capítulo VIII que contiene normas referentes a la misma.

Por su parte, la Ley de la República Popular de China sobre la mediación y el arbitraje de conflictos contractuales sobre tierras rurales del año $2009^{55}$ establece un procedimiento de mediación en su Capítulo II en materias tales como la celebración y terminación de contratos; arrendamiento; y enajenación de la propiedad. ${ }^{56}$

En el caso de la Ley sobre Mediación y Arbitraje de Disputas Laborales de la República Popular de China de 2007 se establece a la mediación y arbitraje como métodos de resolución de conflictos respecto a determinadas disputas de carácter laboral que surjan en el territorio de la República Popular China. ${ }^{57}$ La mediación será llevada adelante ante un Comité de mediación de disputas laborales de la Empresa o por organizaciones municipales o vecinales que tengan como función mediar este tipo de disputas. ${ }^{58}$

54 Vigente desde el 4 de abril de 1991; modificada por primera vez el 28 de octubre de 2007; modificada por segunda vez el 31 de agosto de 2012; y modificada en tercera oportunidad el 27 de Junio de 2017.

55 Promulgada el 27 de junio de 2009 y entrada en vigencia el 1 de enero de 2010.

56 Artículo 2 de la Ley sobre Mediación y Arbitraje de Conflictos Contractuales sobre tierras rurales de República Popular de China.

57 Promulgada el 29 de diciembre de 2007 y entrada en vigencia el 1 de mayo de 2008.

58 Artículo 10 de la Ley sobre Mediación y Arbitraje de Disputas Laborales de la República Popular China. 
Por último, es necesario destacar la Ley de Mediación Popular de la República Popular de China de 2010 que vino a dar un nuevo impulso a este tipo de mediación que con anterioridad estaba regulada por la Reglas Orgánicas para los Comités Populares de 1989 y por primera vez codificada en el año 1954 en las Reglas generales provisionales para la Organización de los Comités Populares. ${ }^{59}$

\section{Tipos de mediación}

A efectos de este trabajo, examino dos tipos de mediación: Mediación Popular y la Mediación Judicial. ${ }^{60}$

\section{A) MEDIACIÓN POPULAR}

Se entiende como mediación popular "a aquél proceso donde las disputas civiles son mediadas por los comités populares de mediación, que son organizaciones establecidas para resolver disputas entre las personas. ${ }^{\prime 16}$ Este tipo de mediación está regulada fundamentalmente en la Ley de Mediación Popular de la República Popular de China (en adelante, LMPCH) de 2010. Así como podemos encontrar otras disposiciones en la Constitución y en la Ley Orgánica de Tribunales Populares de la República Popular de China.

El Capítulo I contiene disposiciones generales. Así, el artículo 2 de la LMPCH señala que la mediación popular se refiere a las actividades del comité de mediación popular para facilitar a las partes para que logren un acuerdo voluntario a través de la persuasión, dando consejos y otros métodos sobre la base de igualdad en la negociación y resolviendo las disputas entre las personas. ${ }^{62}$ De acuerdo con el artículo 7 de la LMPCH: "El comité de mediación popular es una organización comunitaria creada para la mediación de disputas entre las personas que señala la ley". Lo anterior,

59 Promulgada el 28 de agosto de 2010 y entrada en vigencia el 1 de enero de 2011.

60 Podemos distinguir un tercer tipo de mediación denominada institucionalizada, cuya reglamentación proviene de reglas dictadas por instituciones como es el caso del Consejo Chino para la Promoción del Comercio Internacional y la Cámara China de Comercio Internacional y cuya función es establecer la mediación privada en materia comercial. Véase al respecto a

C.H. CHAN (2014).

61 LeE (2014) p. 103.

62 Artículo. 2 de la Ley de Mediación Popular de la República Popular China de 2010. 
está igualmente consagrado en el artículo 5 de las Regulaciones sobre las Organizaciones de los Comités de Mediación Popular ${ }^{63}$, el cual señala que "la tarea de un comité de mediación popular será mediar en disputas privadas, publicitar leyes, reglas administrativas y regulaciones y políticas mediante la mediación y promover la concientización de las leyes, las disciplinas y la moral social entre los ciudadanos."

En los artículos 1 y 6 de la LMPCH se puede encontrar el propósito de la misma; así, el artículo 1 establece: "esta ley ha sido promulgada en cumplimiento de la ley constitucional con el propósito de perfeccionar el sistema de mediación popular, estableciendo pautas para la actividad de mediar, resolver las disputas entre el pueblo de manera oportuna y salvaguardar la armonía y estabilidad de la sociedad". Además el artículo 6 señala: "El Estado fomenta y apoya el trabajo de la mediación popular. Con respecto a los fondos requeridos para el trabajo de la mediación popular, el Gobierno Popular local, de condado y superiores prestarán el apoyo y garantías necesarios. En relación con el comité de mediación populary mediadores populares con contribuciones sobresalientes, serán reconocidos y recompensados en conformidad a la previsión del Estado."

De acuerdo al artículo 3, los comités populares deben observar los siguientes principios al momento de mediar las disputas sometidas a su conocimiento: a) mediar sobre la base de libre albedrío e igualdad de las partes; b) cumplir con las leyes, regulaciones y políticas del Estado; y c) respetar los derecho de las partes y evitar impedir que las partes protejan sus derecho a través de arbitraje, medios administrativos o instancias judiciales. Por último, el artículo señala 4 de la LMPCH que los comités populares no pueden cobran por mediar las disputas sometidas a su conocimiento.

En virtud de lo anterior, es posible concluir que la ley es un claro ejemplo de la importancia de la resolución de disputas y del logro de la armonía y estabilidad en la sociedad china. Claramente, podríamos relacionar estas palabras con las antiguas raíces de la mediación, las ideas del colectivismo chino o la influencia del confucionismo, recordando que el propósito de éste era lograr la armonía.

63 Regulaciones Orgánicas del Comité de Mediación Popular, Consejo de Estado de la República Popular China, aprobadas el 5 de mayo de 1989 y entradas en vigencia el 17 de junio de 1989. 
Por su parte, el Capítulo II de la LMPCH recoge la regulación aplicable a los comités o comisiones populares. Los comités son definidos en el artículo 7 como organizaciones legalmente establecidas para solucionar las disputas de la personas. Podemos encontrar comités populares a nivel de vecindario y de villa, así como es posible que instituciones públicas y empresas los constituyan. ${ }^{64}$ En cuanto al número de miembros, la ley señala que los comités deben estar compuestos de un mínimo de tres hasta nueve miembros.$^{65}$ La ley exige que entre los miembros del comité deben incluirse a mujeres y en áreas de población multiétnicas, deben incluirse a minorías étnicas. ${ }^{66}$

El Capítulo III de la LMPCH está dedicado a los mediadores populares. En este apartado podemos encontrar diferentes disposiciones relacionadas al rol del mediador y la intervención del gobierno en su capacitación. Así por ejemplo, el artículo 14 establece los requisitos para ser mediador. La ley exige que sea un ciudadano adulto con cierto nivel de cultura, política y conocimientos jurídicos. ${ }^{67}$ Asimismo, la actuación del mediador en el procedimiento debe guiarse por la imparcialidad, la decencia y el entusiasmo. ${ }^{68}$

Un aspecto importante de destacar es el rol que tiene el gobierno en la capacitación de un mediador. El parágrafo 2 del artículo 14 pone a cargo del departamento de justicia la preparación periódica de los mediadores. ${ }^{69}$

El Capítulo IV es acerca del procedimiento. De acuerdo al artículo 17, la mediación puede tener lugar por iniciativa de una parte o a iniciativa del comité de mediación popular. ${ }^{70}$ Ésta última es una opción poco común para el mundo occidental, en donde la mediación se considera un procedimiento voluntario, pero en China este rol activo es reconocido y se concede a una institución en orden a intervenir en un procedimiento.

64 Artículo 8 de la Ley de Mediación Popular de la República Popular de China de 2010.

65 Ibíd.

66 Ibid.

67 Artículo 14 de la Ley de Mediación Popular de la República Popular de China de 2010.

68 Ídem.

69 Parágrafo 2 del Artículo 14 de la Ley de Mediación Popular: "El departamento administrativo de justicia a cargo del Gobierno Popular a nivel de condado llevará a cabo, periódicamente, la preparación operacional para los mediadores populares."

70 Artículo 17 de la Ley de Mediación Popular: “Una parte puede solicitar la mediación al comité de mediación popular. El comité de mediación popular también puede tomar la iniciativa de mediar. Cuando una de las partes claramente se niegue a la mediación, ésta no procederá." 
En una clara adopción para fomentar la mediación y evitar litigios, el artículo 18 dispone: "Cuando una disputa es susceptible de ser resuelta a través de la mediación popular, el tribunal popular de primera instancia o el órgano de seguridad puede, antes de aceptar y escucharlos, notificar a las partes de la aplicación de la mediación popular por el comité de mediación popular". El artículo 18 permite a los tribunales administrar el número de casos y, al mismo tiempo, promover a la mediación como método de solución de controversias. Es a discreción del tribunal notificar a las partes, pero claramente es una buena opción hacerles saber acerca de otros caminos para acceder a la administración de justicia.

De conformidad al artículo 19, el comité de mediación popular puede designar a uno o varios mediadores basado en las necesidades del caso, pero esta posibilidad también se concede a las partes..$^{71} \mathrm{El}$ parágrafo primero del artículo 20 es una demostración de lo flexible y completo que puede ser el procedimiento. El mediador popular puede invitar familiares o colegas de las partes, pero solo si estás consienten en ello. También, puede consultar opiniones profesionales e invitar a personal de organizaciones sociales. ${ }^{72}$

El Capítulo V se refiere al acuerdo de mediación. Este acuerdo puede hacerse por escrito o verbalmente. Un acuerdo escrito debe cumplir con ciertas condiciones que establece el artículo 29: (1) Información básica sobre las partes; (2) Principales hechos y materias contenciosas de la controversia, así como las responsabilidades de las partes respectivas; y (3) el contenido, la forma de cumplimiento y los plazos establecidos en el acuerdo celebrado por las partes.

De acuerdo con el artículo 30, el acuerdo verbal tendrá efecto desde el día en que todas las partes han dado su conformidad a él, y en el caso del

71 Artículo 19 de la Ley de Mediación Popular: “El comité de mediación popular puede designar uno o varios mediadores populares para llevar a cabo la mediación basado en las necesidades de la disputa que se media. La partes también pueden seleccionar a uno o varios mediadores populares para llevar a cabo la mediación."

72 Artículo 20 de la Ley de Mediación Popular: "El mediador popular puede invitar a familiares, vecinos o colegas de las partes para ser incorporada en la mediación de acuerdo a las necesidades de la disputa y después del consentimiento dado por las partes. También puede invitar a personas con conocimiento profesional o experiencia específica, o al personal de organizaciones sociales relevantes a participar en la mediación." 
acuerdo escrito, el artículo 29 dispone que tiene lugar cuando cada parte y el mediador lo firmen o coloquen su huella dactilar en él. ${ }^{73}$

El artículo 32 preceptúa que en caso de existir algún conflicto en forma posterior al acuerdo, una de las partes puede presentar una demanda ante el tribunal popular. Con la finalidad de salvaguardar una de las desventajas de la mediación, la falta de ejecución, el artículo 33 de la ley faculta a las partes a solicitar la confirmación del acuerdo. ${ }^{74}$ Las partes pueden hacer esto en el plazo de 30 días desde que el acuerdo escrito o verbal ha desplegado sus efectos. ${ }^{75} \mathrm{Si}$ el Tribunal Popular confirma la validez del acuerdo o una de las partes se niega a cumplirlo, habilita a la contraparte a demandar o exigir la ejecución del mismo. En este caso, el acuerdo tiene la misma validez que una sentencia dictada por un tribunal.

Finalmente, en el caso que los tribunales establezcan que las cláusulas del acuerdo no son válidas, las partes tienen diferentes opciones: pueden modificar el acuerdo original, celebrar uno nuevo o presentar una demanda ante el Tribunal Popular correspondiente.

Por otra parte, es necesario señalar que dentro de las principales críticas se han formulado a la mediación popular destaca la falta de preparación de los mediadores debido a la escasa educación que tienen, situación que se ve acrecentada en las áreas rurales de $\mathrm{China}^{76}$, lo que tiene como consecuencia una deficiente aplicación de la misma. Así, se ha señalado que cerca del $40 \%$ de los mediadores no tienen educación escolar completa. ${ }^{77}$

73 Artículo 29 inciso final de la Ley de Mediación Popular: "El acuerdo escrito tomará sus efectos desde el día en que cada parte firme, estampe su sello o huella dactilar, y el mediador popular firme o estampe el sello del comité de mediación popular. Cada parte tendrá una copia del acuerdo escrito de mediación y el comité de mediación popular retendrá también una copia."

74 Artículo 33 de la Ley de Mediación Popular: "Luego de haber concluido el acuerdo de mediación por el comité de mediación popular, cuando ambas partes lo estimen necesario, ellas pueden dirigirse conjuntamente al Tribunal Popular con el objeto de que éste revise inmediatamente el acuerdo de mediación y confirme su validez de conformidad a la ley."

75 Ibid.

76 LeE (2009) pp. 187 y 188.

77 HUANG (2015) p. 14 . 


\section{B) MediaCión JUdiCIAL}

Cuando hablamos de mediación judicial inmediatamente implicamos la intervención del sistema judicial en el desarrollo de la mediación. En el caso de China, así lo señala Wang Liming: "La mediación judicial es una mediación presidida por jueces que se caracteriza por la intervención y supervisión del Poder Judicial, donde las partes someten, voluntariamente, la resolución de la disputa a la mediación". ${ }^{78} \mathrm{El}$ rol del juez en este caso resulta controversial y problemático porque éste actúa como mediador y adjudicador al mismo tiempo. ${ }^{79}$ Sin perjuicio de lo anterior, el artículo 9 de la Ley de Procedimiento Civil de la República Popular China de 1991 (en adelante LPCCH) ${ }^{80}$ establece que la mediación debe realizarse respetando los principios de voluntariedad y legalidad; y si ella falla, la sentencia se dictará sin mayor retraso.

Es necesario destacar que la ley distingue dos tipos de mediación judicial, la primera se desarrolla con un carácter previo o mediación prejudicial, y la propiamente judicial. En relación con la mediación prejudicial, el artículo 122 señala que cuando la mediación es apropiada para una disputa civil que ya se ha presentado en los tribunales populares, ella debe realizarse primero, a menos que las partes rechacen recurrir a la mediación. Este tipo de mediación es llevada adelante por un juez o un funcionario del tribunal..$^{81}$

Como se señaló con anterioridad, el Capítulo VIII de la LPCCH analiza sistemáticamente la institución de la mediación. De conformidad con el artículo 94, un solo juez o jueces pueden llevar a cabo este tipo de mediación y el tribunal está facultado para utilizar métodos simplificados de notificación a las partes y testigos que participan en la controversia. La razón de ser de este artículo es intentar lograr un procedimiento eficiente y rápido. Asimismo, no es necesario cumplir con todas las formalidades establecidas en un procedimiento civil ante el tribunal.

78 WANG (2009) p. 67.

79 Así, por ejemplo, LeE (2009) p. 105.

80 Vigente desde el 4 de abril de 1991; modificada por primera vez el 28 de octubre de 2007; por segunda vez el 31 de agosto de 2012 y en tercera oportunidad el 27 de Junio de 2017.

81 CHEN (2014) p. 165. 
El artículo 95 permite al tribunal invitar o citar a cualquier persona o institución que pueda resultar relevante para la tramitación de la mediación. ${ }^{82}$ Este artículo extiende los posibles participantes en la resolución de la controversia y es una importante herramienta para ayudar al mediadory a las partes con cualquier tipo de información u opinión que pueda resultar relevante para un mejor entendimiento del conflicto. La razón es que, a mayor información, mayor es la posibilidad de lograr un acuerdo.

El artículo 96 es una manifestación del carácter voluntario del procedimiento. ${ }^{83}$ Las partes son libres para alcanzar un acuerdo y ellas no deben ser forzadas para lograr un acuerdo. El mediador no es un juez, y por ello la ley reconoce a las partes su libertad. Sin embargo, existe solo un límite en torno a alcanzar el acuerdo, y es que éste no puede contravenir la ley.

El artículo 97 regula el procedimiento judicial aplicable luego de que las partes han alcanzado el acuerdo. Generalmente, después de éste, el tribunal dicta una resolución o declaración de acuerdo. La resolución debe contener: a) Las peticiones; b) hechos del caso; c) el resultado de la mediación. Además, debe ser firmado y sellado por el juez y el secretario del tribunal popular, notificando a ambas partes. Es de destacar que la ley señala expresamente que una vez firmada la declaración por ambas partes ella se vuelve vinculante.

Por último, el artículo 98 establece los casos en que no es necesario este tipo de declaración o resolución de acuerdo de mediación. Por ejemplo, en casos de divorcio, adopción, cuando las peticiones pueden ser satisfechas inmediatamente u otros casos que señale la ley. ${ }^{84}$ En tales casos,

82 Artículo 95 de la Ley de Procedimiento Civil: “Cuando se esté llevando a cabo una mediación ante el Tribunal Popular, éste puede invitar unidades o personas interesadas que acudan en su ayuda. Las unidades o personas deberán asistir al Tribunal Popular en la conciliación."

83 Artículo 96 de la Ley de Procedimiento Civil: "El acuerdo debe estar basado en el libre albedrío de ambas partes, y ellas no deben ser forzadas a lograr un acuerdo. El contenido del acuerdo no debe contravenir a la ley."

84 Artículo 98 de la Ley de Procedimiento Civil: "El Tribunal Popular no requerirá realizar una declaración de acuerdo en los siguientes casos en que el acuerdo se ha logrado a través de la mediación:

(1) Casos de divorcio en que ambas partes se han reconciliado luego de la mediación

(2) Casos en que la relación adoptiva se ha mantenido a través de la mediación.

(3) Casos en que las reclamaciones pueden ser satisfechas inmediatamente, $y$

(4) Otros casos que no requieren la declaración de mediación." 
el acuerdo de mediación será vinculante inmediatamente después que las partes, el juez y el secretario firmen en el expediente dando constancia del acuerdo.

Si no existe acuerdo o si una de las partes se retracta del mismo antes de ser notificada, el artículo 99 de la ley señala que el tribunal popular, sin más trámite, emitirá su sentencia. Esta es otra manifestación del acceso a la justicia de manera oportuna e incluso favorece a la mediación, por cuanto las partes saben que, si fracasan en llegar a un acuerdo, la ley garantiza la resolución de la disputa, sin mayores dilaciones.

Como críticas a la mediación judicia se ha puesto en relieve que el juez realiza una doble función al presentarse como mediador y adjudicador; el abuso de autoridad del juez durante la mediación que tiene como efecto forzar a las partes a mediar y evitar el proceso judicial; y, por último, la falta de confidencialidad propia de la mediación no existiría debido al rol de mediador que desempeña el juez..$^{85}$

\section{CONCLUSIONES}

En este trabajo se presentó un breve resumen sobre la mediación en China continental, a partir del cual se ha podido arribar a las siguientes conclusiones:

La mediación tiene sus raíces en la antigua China y fue una eficiente manera de resolver los conflictos en la sociedad. Desde temprano, la mediación envolvía las concepciones filosóficas sobre la armonía y los valores morales dentro de la sociedad. El Confucionismo tuvo una gran trascendencia acerca de cómo la población China resolvía sus disputas y manejaba los conflictos.

El litigio era visto como el último recurso e incluso durante el proceso, las partes tenían la posibilidad de recurrir a la mediación para resolver la controversia. Razones filosóficas y sistémicas justificaban este punto de vista sobre la mediación, por ejemplo, la justicia formal presentaba deficiencias relacionadas con la distancia y la eficiencia, además de la

85 Lee (2014) pp. 110 y 111. 
importancia de instituciones sociales como la familia, las aldeas, que ayudaban a resolver y aislar el conflicto.

Durante las dinastías, la mediación estuvo siempre presente, ya sea como una forma de mediación privada, mediación judicial o administrativa. A lo largo de este período las personas lo utilizaban como un efectivo método de resolución de controversias. La mediación tradicional estuvo presente incluso durante la República.

Con el establecimiento de la República Popular China fuimos testigos de un nuevo desarrollo de la mediación. En efecto, aunque todavía puede recurrir se a los argumentos del colectivismo y del confucionismo para su promoción, el gobierno también la utilizó para educar al pueblo y promover sus ideologías e ideas.

Finalmente, China ha fomentado con éxito la mediación como un método de resolución de controversias porque desde sus inicios, su sociedad y cultura han adoptado un enfoque diferente acerca del manejo de disputas y conflictos, ya que para ellos uno de los valores más importantes es la armonía de la sociedad.

\section{BIBLIOGRAFÍA CITADA}

Barona, Silvia (2011): "Las ADR en la justicia del Siglo XXI, en especial la mediación", Revista Derecho Universidad Católica del Norte, vol. 18 n 1, pp.185-211. Disponible en: http://revistaderecho.ucn.cl/article/ view/2051/1678, fecha de consulta: 11 octubre 2017.

BARONA, Silvia (2014): "Integración de la mediación en el moderno concepto de Access to Justice", InDret, $n^{\circ}$ 4, pp. 2-29. Disponible en: http:// www.indret.com/pdf/1092.pdf, fecha de consulta: 4 noviembre 2017.

Bodde, Derk y Morris, Clarence (1967): Law in imperial China exemplified by 190 Ch'ing Dynasty cases (Cambridge, Harvard University Press).

Bodde, Derk (1981): Essays on Chinese Civilization (New Jersey, Princeton University). 
Bu, Yuanshi y Huo, Xuyang (2015): "The revival of ADR in China: The path to rule of law or the turn against law?", en ESPLUGUES, Carlos y MARQUIS, Luis (editores), New Developments in Civil and Commercial Mediation (The Hague, Springer International Publishing) pp. 191-224.

Chan C.H., Peter C.H. (2014): "Opciones de mediación para resolver disputas comerciales en China", Revista Chilena de Derecho, vol. $41 \mathrm{n}^{\circ}$ 1, pp. 153-170. Disponible en: https://scielo.conicyt.cl/pdf/rchilder/v41n1/ arto7.pdf, fecha de consulta: 7 agosto 2017.

Clark, Kevin C. (2001): "The philosophical underpinning and general workings of Chinese mediation systems: What lessons can American mediators learn?", Pepperdine Dispute Resolution Law Journal, vol. $2 \mathrm{n}^{\circ}$ 1, pp. 117-140. Disponible en: https://digitalcommons.pepperdine. edu/cgi/viewcontent.cgi?refer=https://www.google.com/\&httpsredir=1\&article=1183\&context=drlj, fecha de consulta 6 julio 2017.

COHEN, Jerome A. (1966): "Chinese mediation on the eve of modernization", California Law Review, vol. 54 n 3, pp. 101-121. Disponible en: https:// scholarship.law.berkeley.edu/cgi/viewcontent.cgi?article=2913\&context=californialawreview, fecha de consulta: 20 junio 2017.

ConfuCio (2014): Analectas (Trad. Néstor Cabrera, Madrid, Kailas Editorial).

Dı, Xiaohua y WU, Yunning (2009): "The developing trends of the peoples mediation in China", Sociological Focus Journal, vol. 42 n 3, pp. 228-245. Disponible en: https://www.tandfonline.com/doi/pdf/10.108o/o038 0237.2009.10571354, fecha de consulta: 13 junio 2017.

FOLBERG, Jay y TAYLOR, Alison, (1984): Mediation a comprehensive guide to resolving conflicts without litigation, (San Francisco, Jossey-Bass Publishers).

$\mathrm{GoH}$, Bee Chen (2002): Law without lawyers, justice without courts: on traditional Chinese mediation (Aldershot, Ashgate Publishing).

HeAD, John y WANG,Yanping (2005): Law code in dynastic China (Durham, Carolina Academic Press). 
HILMER, Sarah (2009): Mediation in the People's Republic of China and Hong Kong, (The Hague, Eleven International Publishing).

HuAnG, Yi (2015): "A Study on the People's Mediation System in China: Compared With the Alternative Dispute Resolution (ADR) System in Japan", Frontiers of Legal Research, vol. $3 \mathrm{n}^{\circ}$ 3, pp.12-17. Disponible en: http://www.cscanada.net/index.php/flr/article/view/7728/8502, fecha de consulta: 22 abril 2017.

LeE, Jeffrey K.L. (2014): "Mediation in Mainland China and Hong Kong: Can they learn from each other?", Asian-Pacific Law \& Policy Journal, vol. 16 n $^{\circ}$ 1, pp. 101- 121. Disponible en: http://blog.hawaii.edu/aplpj/ files/2015/01/APLPJ_16.1_Lee.pdf, fecha de consulta: 5 septiembre 2017 .

LI, Xinwei (2017): La Mediación en China: Aportaciones de Occidente (Madrid, Editorial Dykinson).

Lubman, Stanley (1967): "Mao and Mediation: Politics and dispute resolution in Communist China", California Law Review, vol. $55^{\circ}$ 5, pp. 1284-1359. Disponible en: https://scholarship.law.berkeley.edu/cgi/ viewcontent.cgi $?$ article $=2837 \&$ context $=$ californialawreview, fecha de consulta: 7 julio 2017.

TAO, Jingzhou (2005): Resolving disputes in China (The Hague, Kluwer Law International).

WanG, Chang y Madson, Nathan H. (2013): Inside China's Legal System (Oxford, Chandos Publishing).

WANG, Liming (2009): "Characteristic of China's Judicial Mediation System", Asia Pacific Law Review, vol. 17 n 1, pp. 67-74. Disponible en: https:// www.tandfonline.com/doi/pdf/10.1080/10192557.2009.11788207, fecha de consulta: 15 agosto 2017.

$\mathrm{XU}$, Xiaobing (2005): “Different Mediation traditions: A comparison between China and the U.S", American Review of International Arbitration, vol. 16 $\mathrm{n}^{\circ} 3$, pp. 515-545. 
ZenG, Xianyi (2009): "Mediation in China, past and present", Asia Pacific Law Review, vol. $17 \mathrm{n}^{\circ}$ 1, pp. 1-29. Disponible en: https://www.tandfonline.com/doi/pdf/10.1080/10192557.2009.11788203, fecha de consulta: 20 agosto 2017.

ZHANG, Jinfan (2014): The Tradition and Modern Tradition of Chinese Law (Berlin, Heidelberg, Springer).

ZHANG, Yang (2015): "Mediation Model Differences between China and Australia and Their Possible Collaboration", Journal of Interdisciplinary Conflict Science, vol. $1 \mathrm{n}^{\circ}$ 1, pp. 46-58. Disponible en: https://nsuworks.nova.edu/cgi/viewcontent.cgi?article $=1002 \&$ context $=j i c s$, fecha de consulta: 30 mayo 2017.

\section{NORMAS JURÍDICAS CITADAS}

Constitución de la República Popular de China de 1982.

Ley de Procedimiento Civil de la República Popular de China de 1991.

Ley Orgánica de los Tribunales Populares de la República Popular de China de 1979.

Ley de Mediación Popular de la República Popular de China de 2010.

Regulaciones orgánicas del Comité de Mediación Popular de 1989. 